\title{
Immunotherapy for malignant tumors using combination of allogeneic intra-bone marrow-bone marrow transplantation, donor lymphocyte infusion and dendritic cells
}

\author{
HIROMI MUKAIDE ${ }^{1,2}$, YASUSHI ADACHI ${ }^{1,3}$, NAOKO KOIKE-KIRIYAMA ${ }^{1}$, YASUHIRO SUZUKI ${ }^{1}$, \\ KEIZO MINAMINO $^{1}$, MASAYOSHI IWASAKI ${ }^{1}$, MASANOBU TSUDA ${ }^{1}$, KEIJI NAKANO ${ }^{1}$, \\ YASUSHI KOIKE $^{1,2}$, AKIO SHIGEMATSU ${ }^{1}$, YASUO KAMIYAMA ${ }^{2,3}$ and SUSUMU IKEHARA ${ }^{1,3}$ \\ ${ }^{1}$ First Department of Pathology, ${ }^{2}$ Department of Surgery, ${ }^{3}$ Transplantation Center, \\ Kansai Medical University, Moriguchi City, Osaka, Japan
}

Received January 25, 2007; Accepted March 7, 2007

\begin{abstract}
We have previously shown that the combination of allogeneic intra-bone marrow-bone marrow transplantation (IBM-BMT) and donor lymphocyte infusion (DLI) using $\mathrm{CD}^{+}{ }^{+}$cell-depleted spleen cells is effective in suppressing tumor growth, but that this does not induce graft-versus-host disease (GVHD) in mice. In this report, we show that formalinfixed tumor cell-pulsed dendritic cells (FFTCP DCs) have an additive effect with IBM-BMT plus DLI on the suppression of tumor growth, but that the DCs do not augment GVHD. $\mathrm{BALB} / \mathrm{c}$ mice, which had been subcutaneously inoculated with Meth A (BALB/c-derived fibrosarcoma), were irradiated at a low dose ( $5 \mathrm{~Gy}$ ) and were transplanted with bone marrow cells (BMCs) from C57BL/6 (B6) mice into the bone marrow cavity (IBM-BMT). Simultaneously, the mice were intravenously injected with spleen cells from B6 mice, and subcutaneously injected with FFTCP DCs derived from the bone marrow (BM) of B6 mice. At the point of the induction of DCs from BMCs, formalin-fixed Meth A cells were added into the culture. The mice treated with the combination of FFTCP DCs, IBM-BMT and DLI using CD4+ cell-depleted spleen cells showed smaller tumor sizes and longer survival than the mice treated with IBM-BMT plus FFTCP DCs or IBM-BMT plus DLI using CD4+ cell-depleted spleen cells. These results suggest that the combination of FFTCP DCs, IBM-BMT plus DLI using CD4+ cell-depleted spleen cells has potent anti-tumor effects without showing GVHD.
\end{abstract}

Correspondence to: Dr Susumu Ikehara, First Department of Pathology, Kansai Medical University, 10-15 Fumizono-cho, Moriguchi City, Osaka 570-8506, Japan

E-mail: ikehara@takii.kmu.ac.jp

Key words: intra-bone marrow-bone marrow transplantation, donor lymphocyte infusion, dendritic cells, anti-tumor therapy, graft-versushost disease

\section{Introduction}

At present, bone marrow transplantation (BMT) is applied not only to hematopoietic disorders but also malignant solid tumors (1-5). In the case of malignant solid tumors, BMT is expected to show anti-tumor effects. It has been reported that donor lymphocyte infusion (DLI) enhances the anti-tumor effects, although the anti-tumor activity is usually accompanied by GVHD, which is sometimes fatal (3). The fact that the anti-tumor effects are accompanied by GVHD indicates that there may be underlying mechanisms common to both. However, there are also data showing that the anti-tumor effects can be partially distinguished from GVHD, and that DLI has some beneficial effect on the suppression of tumor growth without GVHD (6-11). We have also shown that the combination of IBM-BMT plus DLI using $\mathrm{CD}^{+}$cell-depleted spleen cells helps retain the anti-tumor effects without inducing GVHD in the mouse model (12).

Dendritic cells (DCs) are antigen-presenting cells (APCs) that can prime naive $\mathrm{T}$ cells (13). It has been reported that there is a positive correlation between the number of DCs in tumors and the suppression of the tumor growth, suggesting that DCs infiltrating the tumor cells have some anti-tumor effects (14-16). Based on these findings, anti-tumor therapies using DCs have been tried experimentally and clinically with some success in terms of the suppression of tumor growth. Examples include the administration of fused cells derived from DCs and tumor cells (17), tumor-related peptide-pulsed DCs (18-20) and tumor-related gene-transfected DCs (21). The activation of tumor-specific cytotoxic T lymphocytes (CTLs) has been proposed as a mechanism underlying the anti-tumor effects of these DCs (22). It has been reported that Th1 cells, as well as DC1, which direct naive helper T cells to Th1, play a crucial role in the rejection of tumor cells (23-25).

In this experiment, we carried out the combination therapy of allogeneic IBM-BMT, DLI plus administration of formalinfixed tumor cell-pulsed DCs (FFTCP DCs). We show here that FFTCP DCs enhance the anti-tumor effects of IBMBMT plus DLI using CD4+ cell-depleted spleen cells without showing GVHD. 


\section{Materials and methods}

Animals. C57BL/6 (B6; $\left.\mathrm{H}-2^{\mathrm{b}}\right)$ and BALB/c $\left(\mathrm{H}-2^{\mathrm{d}}\right)$ mice were purchased from Japan SLC, Inc. (Hamamatsu, Japan). B6 mice at the age of 8-12 weeks were used as donors, and $\mathrm{BALB} / \mathrm{c}$ mice at the age of 8 weeks were used as recipients.

Inoculation of tumor cells, and irradiation. For preparation of the subcutaneous tumor model, BALB/c mice were exposed to a radiation dose $\left(3 \mathrm{~Gy}\right.$ at $1.0 \mathrm{~Gy} / \mathrm{min}$ ) from a ${ }^{137} \mathrm{Cs}$ source (Gammacell 40 Exactor; MDS Nordion International Inc., Ottawa, Ontario, Canada) 1 day before subcutaneous injection of the tumor cell line Meth A (mouse fibrosarcoma: H-2d) $\left(5 \times 10^{6}\right.$ cells $\left./ 0.2 \mathrm{ml}\right)$. When the tumor size reached $\sim 10 \times 10 \mathrm{~mm}$, the $\mathrm{BALB} / \mathrm{c}$ mice were exposed to a radiation dose (5 Gy at $1.0 \mathrm{~Gy} / \mathrm{min}$ ) from a ${ }^{137} \mathrm{Cs}$ source. One day later, IBM-BMT, DLI plus subcutaneous injection of FFTCP DCs were performed. As controls, groups receiving: i) tumor-inoculated mice without IBM-BMT (control), ii) IBM-BMT (IBM-BMT), iii) IBM-BMT plus DLI using whole spleen cells [IBM-BMT + DLI (whole)], iv) IBM-BMT plus injection of DCs (IBM$\mathrm{BMT}+\mathrm{DC}$ ) were prepared.

For preparation of the lung metastasis model, BALB/c mice were exposed to a radiation dose $(5 \mathrm{~Gy}$ at $1.0 \mathrm{~Gy} / \mathrm{min}$ ) from a ${ }^{137} \mathrm{Cs}$ source $5 \mathrm{~h}$ before intravenous injection of the tumor cell line Meth A $\left(1 \times 10^{6}\right.$ cells $\left./ 0.2 \mathrm{ml}\right)$. The day after irradiation, IBM-BMT, DLI plus injection of cultured DCs were performed.

IBM-BMT and DLI. Bone marrow cells (BMCs) were harvested from the femoral, tibial bones and pelves of $\mathrm{B} 6$ mice and suspended in phosphate-buffered saline (PBS). The BMCs were then filtered through a 70- $\mu$ m-nylon wool mesh (Becton Dickinson Labware, Franklin Lakes, NJ) and centrifuged at $1,500 \mathrm{rpm}$ for $7 \mathrm{~min}$ at $4^{\circ} \mathrm{C}$. After centrifugation, the BMCs were suspended and adjusted to $3.0 \times 10^{9}$ cells $/ \mathrm{ml}$ in PBS containing $2 \%$ fetal calf serum (FCS). Thus-prepared BMCs $\left(3.0 \times 10^{7}\right)$ were injected directly into the bone marrow cavity of the tibial bones (IBM-BMT), as previously described (26). Briefly, the region from the inguen to the knee joint was shaved. The knee was flexed to 90 degrees, and the proximal side of the tibia was drawn to the anterior. A 26-gauge needle was inserted into the bone marrow cavity. Using a microsyringe (50 $\mu \mathrm{l}$; Ito, Fuji, Japan) containing the donor BMCs $\left(3 \times 10^{7}\right.$ cells $/ 10 \mu 1$ ), the donor BMCs were injected from the side bone hole into the bone marrow cavity.

DLI was performed as follows: spleens were removed from donor B6 mice and then minced with scissors. Single cells were prepared by passing the minced spleen through stainless steel mesh in PBS containing 2\% FCS. After centrifugation at 2,000 rpm for $10 \mathrm{~min}$ at $20^{\circ} \mathrm{C}$, the pellets were suspended in $\mathrm{PBS}$ containing $2 \% \mathrm{FCS}$, then adjusted to $2.0 \times 10^{7}$ cells/ $0.2 \mathrm{ml}\left(1.0 \times 10^{8}\right.$ cells $\left./ \mathrm{ml}\right)$ in PBS containing $2 \% \mathrm{FCS}$. In some experiments, $\mathrm{CD}^{+}{ }^{+}$cell-depleted spleen cells were prepared using Dynabeads (Dynal A.S., Oslo, Norway) by the treatment of spleen cells with biotin-coupled anti-CD4 mAb (Pharmingen, San Diego, CA) and biotin-coupled anti-TER-119/erythroid cell mAb (Pharmingen) plus avidin-coupled Dynabeads.

Preparation of bone marrow-derived dendritic cells (DCs). BMCs were obtained from B6 mice, and mononuclear cells were separated from the BMCs by centrifugation with lymphoprep. DCs were induced by culture of mononuclear cells in the presence of GM-CSF (10 ng/ml), IL-3 (10 ng/ml), IL-12 (10 ng/ml), INF- $\gamma(10 \mathrm{ng} / \mathrm{ml})$ and formalin-fixed Meth A for 4 days, as previously described (23). DCs were harvested from the culture at day 4 and used for the experiments. The cultured DCs were injected subcutaneously into BALB/c mice. The recombinant murine GM-CSF, IL-3, IL-12 and INF- $\gamma$ were purchased from PeproTech EC (London, UK).

Measurement of body weight and tumor size. Body weight and tumor size were measured every other day. In all experiments, the mice were weighed on a weighing machine, and the weight was expressed in grams. Tumor size was measured by vernier calipers and expressed as width $(\mathrm{mm}) \mathrm{x}$ length $(\mathrm{mm})$ $\mathrm{x}$ height $(\mathrm{mm})=$ tumor size $\left(\mathrm{mm}^{3}\right)$.

Assessment of GVHD. Macroscopically GVHD was assessed by weight loss, hunching posture, loss of activity, ruffled hair and diarrhea. It was also assessed microscopically by the infiltration of lymphocytes into the liver (27).

Statistical analysis. Survival data were analyzed using the Kaplan-Meier method in the Stat Mate software. Statistical differences between groups were analyzed using the log-rank test in the Stat Mate software. $\mathrm{p}<0.05$ was considered to be significant.

\section{Results}

FFTCP DCs can augment anti-tumor effects of DLI plus $I B M-B M T$. We have previously reported that the combination of allogeneic IBM-BMT plus DLI has anti-tumor effects on mouse fibrosarcoma, Meth A (12). As shown in our previous report, the tumor sizes of mice treated with 'IBM-BMT + DLI (whole)' $\left(10,500 \pm 5,200 \mathrm{~mm}^{3}\right.$ at 30 days after BMT) were smaller than those of 'IBM-BMT' $\left(12,400 \pm 6,000 \mathrm{~mm}^{3}\right)$, 'IBM-BMT + DC' $\left(11,800 \pm 5,400 \mathrm{~mm}^{3}\right)$ or non-treated mice $\left(26,000 \pm 15,000 \mathrm{~mm}^{3}\right)$ (Fig. 1). Next, we examined whether FFTCP DCs can enhance the anti-tumor effects of 'IBMBMT + DLI (whole)', using the mice injected with Meth A subcutaneously, since it has been reported that tumor antigenpulsed auto-DCs have some suppressive effects on tumor growth (18-20) and syngeneic FFTCP DCs suppress the growth of tumor cells (unpublished data). The tumors in the mice treated with the combination of IBM-BMT, DLI plus FFTCP DC injection ['IBM-BMT + DLI (whole) + DC'] $\left(6,600 \pm 3,800 \mathrm{~mm}^{3}\right)$ were smaller than those of 'IBM-BMT + DLI (whole)' $\left(10,500 \pm 5,200 \mathrm{~mm}^{3}\right)$ or 'IBM-BMT + DC' $\left(11,800 \pm 5,400 \mathrm{~mm}^{3}\right)$. These results suggest that FFTCP DCs can enhance the effects of IBM-BMT plus DLI, resulting in the suppression of tumor growth. Previously, we have reported that the combination of IBM-BMT plus DLI using $\mathrm{CD}^{+}{ }^{+}$cell-depleted spleen cells [IBM-BMT + DLI(CD4 $\left.\left.{ }^{-}\right)\right]$ shows anti-tumor effects without showing prominent GVHD. Therefore, we examined the anti-tumor effects of the combination of IBM-BMT, DLI using $\mathrm{CD}^{+}{ }^{+}$cell-depleted spleen cells plus FFTCP DCs [IBM-BMT + DLI(CD4-) + DC] 'IBM-BMT + DLI(CD4-) + DC' also showed anti-tumor effects $\left(2,700 \pm 600 \mathrm{~mm}^{3}\right)$ similar to the combination of FFTCP DCs, 
A.
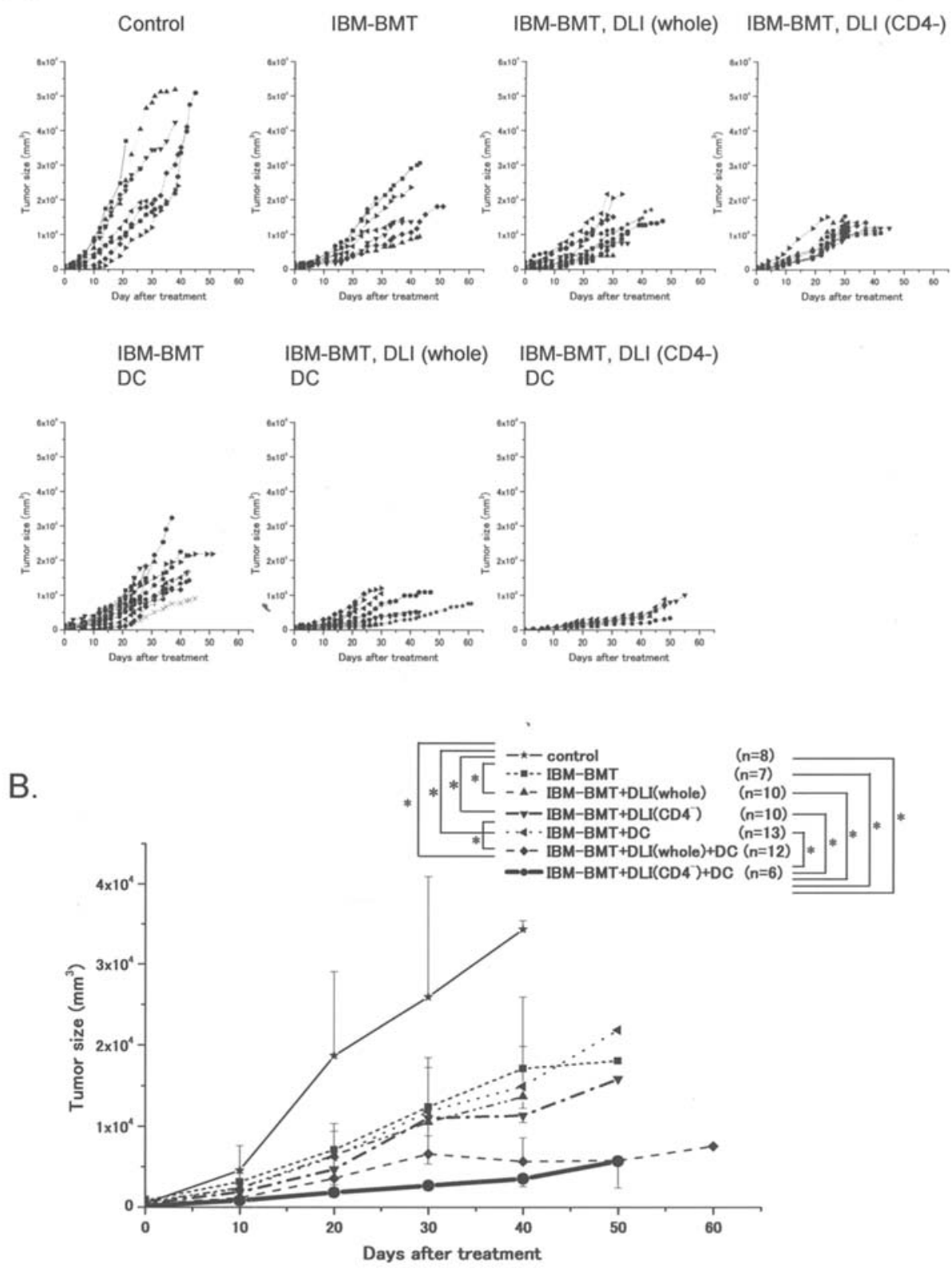

Figure 1. The effects of the combination of FFTCP DCs, IBM-BMT plus DLI on subcutaneously injected sarcoma. BALB/c mice were irradiated at 3 Gy and were inoculated with Meth A cells subcutaneously. When the tumor had grown to approximately $1 \mathrm{~cm}$ in diameter, the mice were irradiated at 5 Gy and were transplanted with bone marrow cells (BMCs) from B6 mice into the bone cavity (intra-bone marrow-bone marrow transplantation; IBM-BMT) and were intravenously transplanted with spleen cells from B6 mice. Simultaneously, the mice were subcutaneously injected with FFTCP DCs, which had been derived from the BMCs of B6 mice. Tumor size was measured every other day. Several experimental groups were prepared as follows. i) 'Control' indicates subcutaneous injection of Meth A cells, only. ii) 'IBM-BMT' indicates subcutaneous injection of Meth A cells and IBM-BMT from B6 mice. iii) 'IBMBMT+DLI (whole)' indicates subcutaneous injection of Meth A cells, IBM-BMT from B6 mice, DLI using whole spleen cells of B6 mice. iv) 'IBMBMT+DC' indicates subcutaneous injection of Meth A cells, IBM-BMT from B6 mice and subcutaneous injection of FFTCP DCs derived from BMCs of B6. v) 'IBM-BMT+DLI (whole)+DC' indicates subcutaneous injection of Meth A cells, IBM-BMT from B6 mice, DLI using whole spleen cells of subcutaneous injection of FFTCP DCs derived from BMCs of B6. vi) 'IBM-BMT + DLI (CD4') + DC' indicates subcutaneous injection of Meth A cells, IBM-BMT from B6 mice, DLI using CD4+ cell-depleted spleen cells of subcutaneous injection of FFTCP DCs derived from BMCs of B6 mice. Changes in tumor sizes in individual mice (A) and means and SD (B) in each group are shown. " $\mathrm{p}<0.05$ versus 'control group'.

IBM-BMT plus DLI using whole spleen cells ('IBM-BMT + DLI (whole) + DC') $\left(6,600 \pm 3,800 \mathrm{~mm}^{3}\right)$.

FFTCP DCs do not enhance graft versus host disease $(G V H D)$. As shown in Fig. 3 and also our previous report, DLI using whole spleen cells reduced the tumor sizes but enhanced GVHD, resulting in no significant prolongation of survival time in comparison with only allogeneic IBMBMT, since the mice died not due to the tumors themselves but of GVHD. Survival times in the control group, 'IBMBMT', and 'IBM-BMT + DLI (whole)' were 34.6 \pm 8.5 , $40.3 \pm 7.0$ and 33.7 \pm 7.0 days, respectively. 'IBM-BMT + DLI (whole) + DC' suppressed the growth of the tumor but did not significantly reduce survival rates $(34.2 \pm 12.0$ days $)$. 

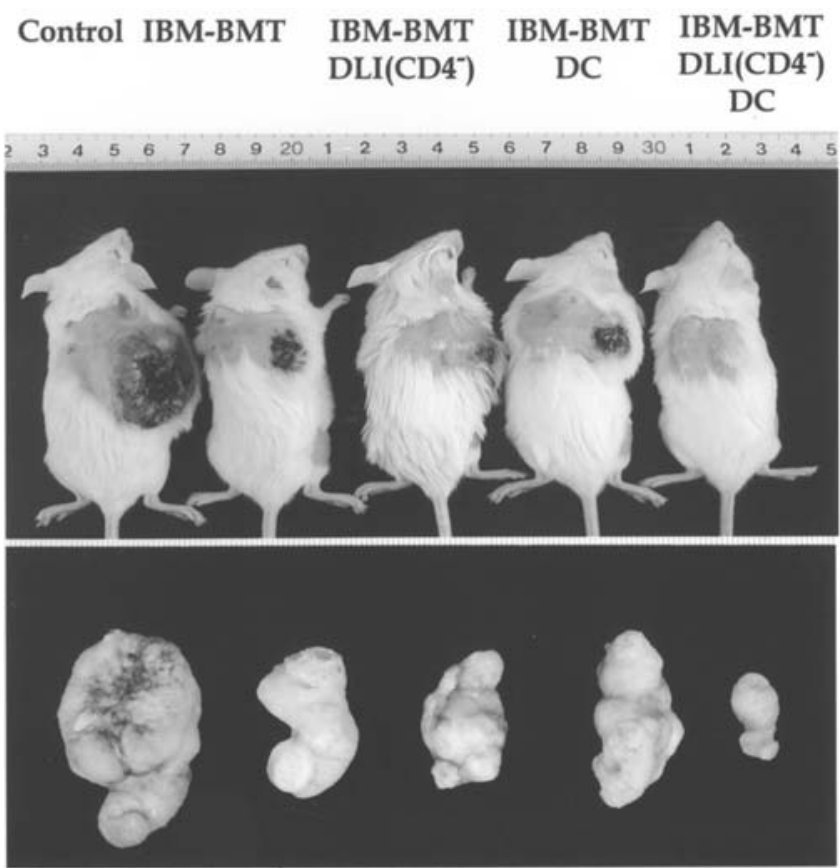

Figure 2. Macroscopical appearance of tumors in each group. Representative macroscopical appearances of tumors in each group 14 days after IBM-BMT are shown. In control mice, the tumor is shown 10 days after the tumor attained $1 \mathrm{~cm}$ in diameter. The upper photograph shows inoculated tumors and the lower photograph shows removed tumors. The sizes of tumors of the mice treated with 'IBM-BMT + DLI(whole $)+$ DC' were similar to those of the mice treated with 'IBM-BMT + DLI(CD4) + DC' (data not shown).

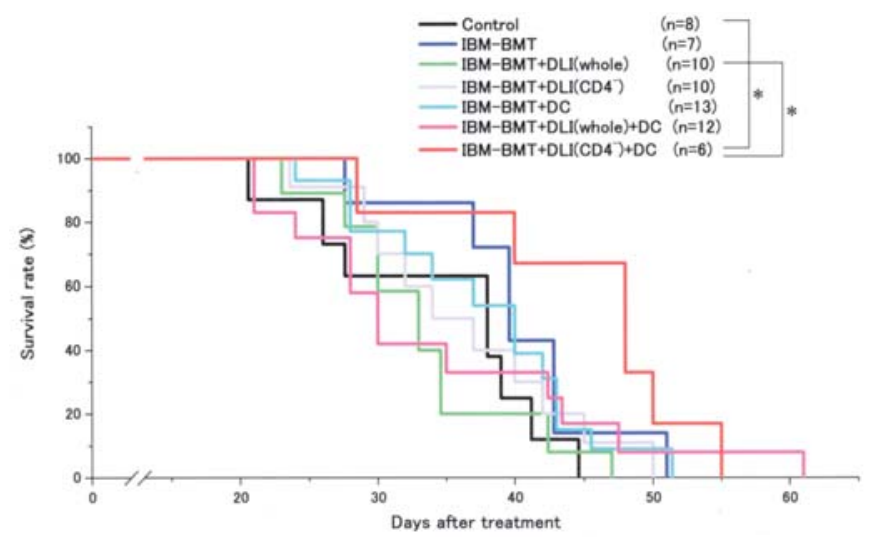

Figure 3. Survival rate of each group of mice subcutaneously injected with Meth A cells. Survival rates of mice in each group are shown. Indicated days show the passage of time after IBM-BMT (groups except for control group) and days after tumors attained $1 \mathrm{~cm}$ in diameter. ${ }^{*} \mathrm{p}<0.05$ versus 'control group'.

'IBM-BMT + DLI(CD4-) + DC' showed no clear evidence of GVHD clinically or histologically, and there was a significant prolongation of survival time $(44.8 \pm 9.6$ days). These results suggest that the FFTCP DCs do not enhance GVHD induced by DLI, and that the usage of FFTCP DCs has the benefit of enhancing anti-tumor effects without enhancing GVHD.

Effects of 'IBM-BMT + DLI(CD4-) + DC' on lung metastatic model. The above data suggest that 'IBM-BMT + DLI(CD4')

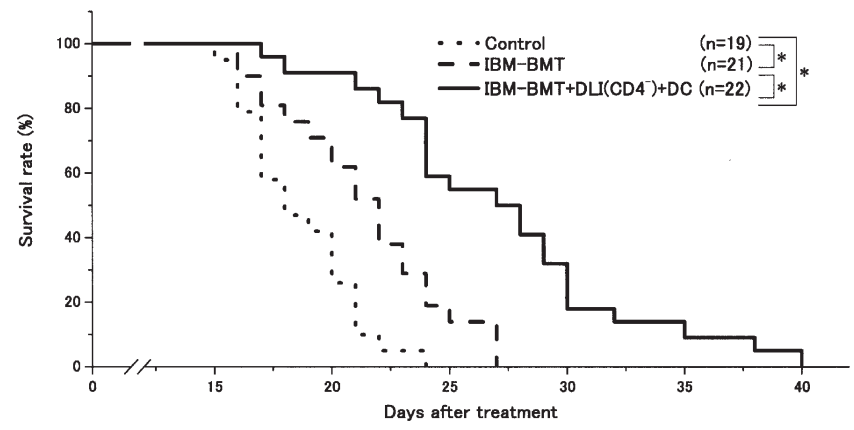

Figure 4. Survival rates in the mice intravenously injected with Meth A cells. Three Gy-irradiated BALB/c mice were intravenously injected with Meth A cells. Twelve hours after the injection of Meth A, the BALB/c mice were treated with IBM-BMT using BMCs from B6 mice (IBM-BMT) or IBM-BMT using B6 mice and DLI using $\mathrm{CD}^{+}{ }^{+}$cell-depleted spleen cells of B6 ['IBM-BMT + DLI(CD4-) + DC']. Control consisted of the injection of only Meth A cells. The horizontal axis shows the passage of days after injection of Meth A cells. " $\mathrm{p}<0.05$ versus 'control group'.

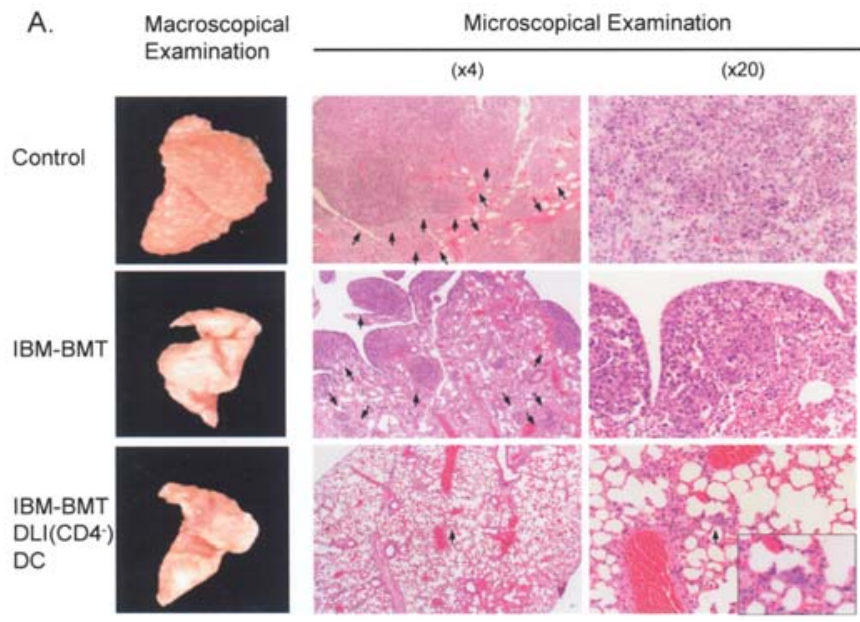

B.

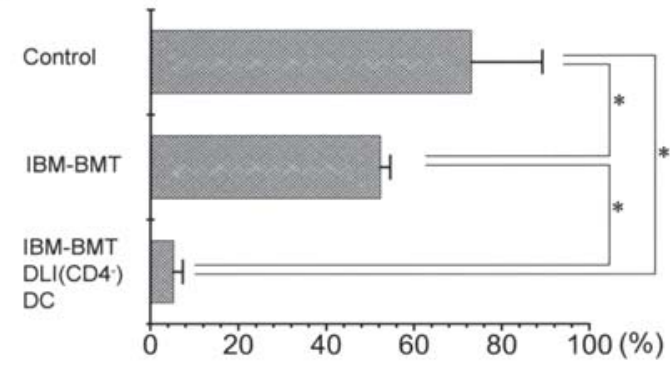

Figure 5. Macroscopical and histological examination of the lungs in each group. Five Gy-irradiated BALB/c mice were intravenously injected with Meth A cells. Twelve hours after the injection of Meth A, the BALB/c mice were treated with 'IBM-BMT' or 'IBM-BMT + DLI(CD4-) + DC'. Control consisted of the injection of only Meth A cells. Mice were sacrificed at 14 days after injection of Meth A cells. The lungs of each group were fixed with formalin. Representative data of the macroscopical photograph and the microscopical photographs (A) and means and SDs of \% of tumor occupied area (B) in the lungs in each group are shown. Arrows show tumor nodules. "p $<0.05$.

+ $\mathrm{DC}^{\prime}$ is the best strategy in this experiment; this combination has potent anti-tumor effects but does not induce GVHD. Therefore, we next applied this combination therapy to the 
lung metastatic model. A 'lung metastatic model of the sarcoma' was prepared as described in Materials and methods. When the tumor cells were injected into the vein, multiple metastatic lesions of the sarcoma grew rapidly, and the mice died rapidly $(18.7 \pm 2.5$ days $)$ in comparison with the mice subcutaneously injected with the tumor cells (Fig. 4). Therefore, in this model, we can easily compare the effects of the treatments by survival time. As shown in Fig. 4, the mice treated with 'IBM-BMT' showed a slightly improved survival time $(21.5 \pm 3.1$ days $)$, and the mice treated with 'IBM-BMT + DLI(CD4-) + DC' showed significantly longer survival time (27.2 \pm 4.2 days) in comparison with control mice $(18.7 \pm 2.5$ days $)$ or the mice treated with 'IBM-BMT' (21.5 \pm 3.1 days).

To clarify the effects of 'IBM-BMT + DLI (CD4') + DC', we examined the lungs macroscopically and microscopically 10 days after injection of Meth A cells (Fig. 5). In the macroscopical examination, many micronodules were observed in the lungs of mice just injected with Meth A cells. Fewer, and smaller, nodules were seen in the lungs of mice treated with 'IBM-BMT' than in the control mice, while there were no nodules in the lungs of mice treated with 'IBM-BMT + DLI(CD4-) + DC'; in these mice, lung morphology was similar to normal lung. In the microscopical examination, many large masses of the tumor cells were seen in the lungs of control mice, while fewer and smaller tumor masses were seen in the lungs of the mice treated with 'IBM-BMT'. Very few tumor cells were seen in the lungs of mice treated with 'IBM-BMT + DLI(CD4-) + DC'. These results suggest that there is significant suppression of tumor growth in the lungs of mice treated with 'IBM-BMT + DLI (CD4') + DC', and that there is no GVHD.

\section{Discussion}

Recently, we have found that allogeneic BMT plus DLI using donor CD8-depleted spleen cells enhances GVHD, followed by induction of early death of recipients, and that allogeneic BMT plus DLI using donor CD4-depleted spleen cells prolonged survival due to the suppression of tumor growth in not only malignant tumor carrying mice but also rats $(12,28)$. In these experiments, we confirmed that allogeneic BMT plus DLI using CD4-depleted spleen cells has a beneficial effect on the suppression of tumor growth and reduction of GVHD. It has been reported that DLI accelerates successful donor engraftments (29), and that DLI is successfully used for some life-threatening viral infections after stem cell transplantation (30-33). We have also reported that IBM-BMT accelerates donor hematopoiesis after allogeneic BMT (26). Therefore, it is conceivable that IBM-BMT with DLI could reduce the probability and severity of infections due to both infusion of mature immune cells by DLI and rapid recovery of immune cells from donor hematopoietic stem cells by IBM-BMT. This reduction of probability and severity of infection, in addition to its anti-tumor effect, is an advantage of IBM-BMT plus DLI.

Tumor antigen-pulsed DCs and the combination of BMT plus DLI have been used as potential therapeutic strategies for malignant solid tumors $(3,18,19,34,35)$. In this report, we show that the combination of FFTPC DCs derived from donor BMCs, allogeneic IBM-BMT and DLI suppresses the growth of solid tumors more effectively than FFTPC DC alone or the combination of allogeneic IBM-BMT and DLI. Moreover, the FFTPC DC did not augment GVHD of allogeneic IBM-BMT plus DLI. These results suggest that the FFTPC DCs have additive effects on immunotherapy using allogeneic BMT plus DLI for solid tumors.

It has been reported that helper $\mathrm{T}$ cells can be classified into several subsets, such as Th0, Th1, Th2 and Th3 cells $(36,37)$. Th0 cells are reported to be immature helper T cells that differentiate into Th1, Th2 or Th3 cells (38). Th1 cells characteristically secrete IL- 2 and INF- $\gamma$, while Th2 cells specifically secrete IL-4, IL-5 and IL-6, and Th3 cells are characterized to secrete TGF- 3 (36-39). Therefore, Th1 cells augment cellular immunity and suppress humoral immunity, while Th2 cells augment humoral immunity and suppress cellular immunity. On the other hand, Th3 cells suppress various immunofunctions. The balance of Th1/Th2 is important to maintain normal immunoreactions, such as the defense against infections and suppression of autoimmune diseases (36-39). It has been reported that the direction toward Th1 is important for the suppression of tumor growth (25). It has also been reported that DCs play a crucial role in the activation of T cells, and determine the direction toward Th1 or Th2 from Th0. On the basis of these facts, DCs have been divided into 2 groups (DC1 and DC2): DC1 cells direct helper T cells toward Th1 cells and DC2 cells direct helper $\mathrm{T}$ cells toward Th2 cells $(23,24)$. Recently, the effects of DC1 or DC2, which had been derived from BMCs using GM-CSF and some other cytokines, on malignant tumors were extensively examined. It was reported that DC1 suppressed the tumor growth, and that DC1 plus Th1 significantly suppressed the tumor growth and improved the survival rate (24). On the basis of the experiment, we induced DC1 from the donor BMCs and added formalin-fixed tumor cells to the culture of BMCs to promote the efficient uptake of tumor antigens by the DCs, since immature DCs show more efficient uptake of antigens than mature DCs, and tumor antigen-pulsed DCs have been reported to be effective in the treatment of several cancers in humans. We examined the effects of the combination of thus-induced FFTCP DCs and allogeneic IBM-BMT + DLI, which we have previously shown to be effective in the suppression of tumors. As we expected, the strategy suppressed tumor growth more effectively than 'IBM-BMT + DLI'. It has been reported that GVHD is related to activation of Th1 but, contrary to our predictions, the combination did not augment GVHD. This is likely due to the IBM-BMT, since IBM-BMT can efficiently recruit donor-derived stromal cells, which produce immunosuppressive cytokines such as TGF- $\beta$, HGF, IL-10 and IL-15 (40-48).

To distinguish graft versus tumor reaction from GVHD, several kinds of strategies have been tried. One such strategy is to prepare a mixed chimera of hematopoietic cells. In the murine system, it was described that the mixed chimera of donor hematopoietic cells and recipient hematopoietic cells reduced the frequency and severity of GVHD (49). Based on these findings, the mixed chimera was applied to human BMT. In some cases, the mixed chimera was successful in reducing GVHD (50). However, some researchers have 
reported that GVHD still occurs where there is a mixed chimera in the peripheral blood of the recipients $(51,52)$. Therefore, even in human BMT, IBM-BMT plus DLI could be a useful alternative strategy for suppressing GVHD.

There was very little metastasis of the tumor inoculated subcutaneously in our experiment (data not shown). Therefore, we next injected tumor cells intravenously to induce the lung metastatic model and then examined the effects of our strategy on malignant metastatic tumors. In the model, the tumor cells formed multiple nodules in the lungs and induced rapid death of the mice. In the experiment, we used the $\mathrm{CD}^{+}$ cell-depleted spleen cells for DLI, since we have previously shown that DLI using $\mathrm{CD}^{+}{ }^{+}$cell-depleted spleen cells has anti-tumor effects but does not induce GVHD (9). The combination significantly prolonged the survival time of the mice intravenously injected with tumor cells. These results suggest that FFTCP DCs and DLI using CD4+ cell-depleted spleen cells augments the anti-tumor effects of allogeneic IBM-BMT but does not augment GVHD. Therefore, we here propose that anti-tumor effects without augmentation of GVHD can be induced by the combination of IBM-BMT, DLI and DC-pulse therapy in humans.

\section{Acknowledgments}

We thank Ms. Miura, Ms. Murakami-Shinkawa, Ms. Tokuyama, Ms. Hayashi and Ms. Kitajima for their expert technical assistance, and also Mr. Hilary Eastwick-Field and Ms. Ando for the preparation of this manuscript. This study was supported by grants from the 'Millennium' program of the Ministry of Education, Culture, Sports, Science and Technology, and the 'Science Frontier' program of the Ministry of Education, Culture, Sports, Science and Technology, a grant-in-aid for scientific research (B)11470062, grants-inaid for scientific research on priority areas (A)10181225 and (A)11162221, and Health and Labour Sciences research grants (Research on Human Genome, Tissue Engineering Food Biotechnology), The 21st Century Center of Excellence Program (project leader), and The Ministry of Education, Culture, Sports, Science and Technology and also grants from the Department of Transplantation for Regeneration Therapy (sponsored by Otsuka Pharmaceutical Company, Ltd.); Molecular Medical Science Institute, Otsuka Pharmaceutical Co., Ltd.; and Japan Immunoresearch Laboratories Co., Ltd. (JIMRO).

\section{References}

1. Childs R, Chernoff A, Contentin N, et al: Regression of metastatic renal-cell carcinoma after non-myeloablative allogeneic peripheral-blood stem-cell transplantation. N Engl J Med 343: 750-758, 2000.

2. Zetterquist $\mathrm{H}$, Hentschke $\mathrm{P}$, Thorne $\mathrm{A}$, et al: A graft-versuscolonic cancer effect of allogeneic stem cell transplantation. Bone Marrow Transplant 28: 1161-1166, 2001.

3. Anderlini P, Acholonu SA, Okoroji G-J, et al: Donor leukocyte infusions in relapsed Hodgkin's lymphoma following allogeneic stem cell transplantation: $\mathrm{CD}^{+}$cell dose, GVHD and disease response. Bone Marrow Transplant 34: 511-514, 2004.

4. Eibl B, Schwaighofer H, Nachbaur D, et al: Evidence for a graft-versus-tumor effect in a patient treated with marrow ablative chemotherapy and allogeneic bone marrow transplantation for breast cancer. Blood 88: 1501-1508, 1996.
5. Slavin S, Morecki S, Weiss L and Or R: Donor lymphocyte infusion: the use of alloreactive and tumor-reactive lymphocytes for immunotherapy of malignant and nonmalignant diseases in conjunction with allogeneic stem cell transplantation. J Hematother Stem Cell Res 11: 265-276, 2002.

6. Tsukada N, Kobata T, Aizawa Y, Yagita H and Okumura K: Graft-versus-leukemia effect and graft-versus-host disease can be differentiated by cytotoxic mechanisms in a murine model of allogeneic bone marrow transplantation. Blood 93: 2738-2747, 1999.

7. Hattori K, Hirano T, Miyajima H, et al: A metalloproteinase inhibitor prevents acute graft-versus-host disease while preserving the graft-versus-leukaemia effect of allogeneic bone marrow transplantation. Br J Haematol 105: 303-312, 1999.

8. Ruggeri L, Capanni M, Urbani E, et al: Effectiveness of donor natural killer cell alloreactivity in mismatched hematopoietic transplants. Science 295: 2097-2100, 2002.

9. Yung I, Weiss L, Abdul-Hai A, Kasir J, Reich S and Slavin S: Induction of early post-transplant graft-versus-leukemia effects using intentionally mismatched donor lymphocytes and elimination of alloantigen-primed donor lymphocytes for prevention of graft-versus-host disease. Cancer Res 65: 9735-9740, 2005.

10. Luznik L, Slansky JE, Jalla S, Borrello I, Levitsky HI, Pardoll DM and Fuchs EJ: Successful therapy of metastatic cancer using tumor vaccines in mixed allogeneic bone marrow chimeras. Blood 101: 1645-1652, 2003.

11. Slavin S, Ackerstein A, Morecki S, Gelfand Y and Cividalli G: Immunotherapy of relapsed resistant chronic myelogenous leukemia post allogeneic bone marrow transplantation with alloantigen pulsed donor lymphocytes. Bone Marrow Transplant 28: 795-798, 2001.

12. Suzuki Y, Adachi Y, Minamino K, et al: A new strategy for treatment of malignant tumor: intra-bone marrow-bone marrow transplantation plus CD4- donor lymphocyte infusion. Stem Cells 23: 365-370, 2005.

13. Steinman RM: The dendritic cell system and its role in immunogenicity. Annu Rev Immunol 9: 271-296, 1991.

14. Tsujitani S, Furukawa Y, Tamada R, Okumura T, Yasumoto K and Sugimachi K: Langerhans cells and prognosis in patients with gastric carcinoma. Cancer 59: 501-505, 1987.

15. Schronder S, Schwarz W, Rehpenning W, Loning T and Bocker W: Dendritic/langerhans cells and prognosis in patients with papillary thyroid carcinomas, immunocytochemical study of 106 thyroid neoplasms correlated to follow-up data. Am J Clin Pathol 89: 295-300, 1988.

16. Furihata M, Ohtsuki Y, Ido E, et al: HLA-DR antigen- and S-100 protein-positive dendritic cells in esophageal squamous cell carcinoma - their distribution in relation to prognosis. Virchows Arch B Cell Pathol Incol Mol Pathol 61: 409-414, 1992.

17. Gong J, Chen D, Kashiwaba M and Kufe D: Induction of antitumor activity by immunization with fusions of dendritic and carcinoma cells. Nat Med 3: 558-561, 1997.

18. Ikuta Y, Okugawa T, Furugen R, et al: A HER2/neu-derived peptide, a Kd-restricted murine tumor rejection antigen, induces HER2-specific HLA-A2402-restricted CD8+ cytotoxic T lymphocytes. Int J Cancer 87: 553-558, 2000.

19. Tsunoda $T$, Tanimura $H$, Yamaue $H$, Tanaka $H$ and Matsuda $K$ : Tumor specific CTL therapy for advanced cancer and development for cancer vaccine. Hepatogastroenterology 46: 1287-1292, 1999.

20. Tjoa BA, Elgamal AA and Murphy GP: Vaccine therapy for prostate cancer. Urol Clin North Am 26: 365-374, 1999.

21. Tuting T, Wilson CC, Martin DM, et al: Autologous human monocyte-derived dendritic cells genetically modified to express melanoma antigens elicit primary cytotoxic $\mathrm{T}$ cell responses in vitro: enhancement by cotransfection of genes encoding the Th1-biasing cytokines IL-12 and IFN-alpha. J Immunol 160: 1139-1147, 1998

22. Peshwa MV, Shi JD, Ruegg C, Laus R and van Schooten WCAV: Induction of prostate tumor-specific $\mathrm{CD}^{+}$cytotoxic T-lymphocytes in vitro using antigen-presenting cells pulsed with prostatic acid phosphatase peptide. Prostate 36: 129-138, 1998.

23. Sato M, Iwakabe K, Kimura $S$ and Nishimura T: Functional skewing of bone marrow-derived dendritic cells by Th1- or Th2-inducing cytokines. Immunol Lett 67: 63-68, 1999.

24. Sato M, Iwakabe K, Ohta A, et al: Functional heterogeneity among bone marrow-derived dendritic cells conditioned by Th1- and Th2- biasing cytokines for the generation of allogeneic cytotoxic T lymphocytes. Int Immunol 12: 335-342, 2000. 
25. Nishimura T, Iwakabe $\mathrm{K}$, Sekimoto $\mathrm{M}$, et al: Distinct role of antigen-specific T helper type 1 (Th1) and Th2 cells in tumor eradication in vivo. J Exp Med 190: 617-627, 1999.

26. Kushida $\mathrm{T}$, Inaba $\mathrm{M}$, Hisha $\mathrm{H}$, et al: Intra-bone marrow injection of allogenic bone marrows: a powerful new strategy for treatment of intractable autoimmune diseases in MLR/lpr mice. Blood 97: 3292-3299, 2001.

27. Cooke KR, Kobzik L, Martin TR, Brewer J, Delmonte J, Crawford JM and Ferrara JLM: An experimental model of idiopathic pneumonia syndrome after bone marrow transplantation: I. the roles of minor $\mathrm{H}$ antigens and endotoxin. Blood 8: 3230-3239, 1996.

28. Koike Y, Adachi Y, Suzuki Y, et al: Allogeneic intra-bone marrow-bone marrow transplantation plus donor lymphocyte infusion suppresses growth of colon cancer cells implanted in skin and liver of rats. Stem Cells (In press)

29. Barge RM, Osanto S, Marijt WA, et al: Minimal GVHD following in vitro $\mathrm{T}$ cell-depleted allogeneic stem cell transplantation with reduced-intensity conditioning allowing subsequent infusions of donor lymphocytes in patients with hematological malignancies and solid tumor. Exp Hematol 31: 865-872, 2003.

30. Papadopoulos EB, Ladanyi M, Emanuel D, et al: Infusions of donor leukocytes to treat Epstein-Barr virus-associated lymphoproliferative disorders after allogeneic bone marrow transplantation. N Engl J Med 330: 1185-1191, 1994.

31. Kishi Y, Kami M, Oki Y, et al: Donor lymphocyte infusion for treatment of life-threatening respiratory syncytial virus infection following bone marrow transplantation. Bone Marrow Transplant 26: 573-576, 2000.

32. Hromas R, Cornetta K, Srour E, Blanke C and Broun ER: Donor leukocyte infusion as therapy of life-threatening adenoviral infections after T-cell-depleted bone marrow transplantation. Blood 84: 1689-1690, 1994.

33. Yoshihara S, Kato R, Inoue T, et al: Successful treatment of life-threatening human herpesvirus-6 encephalitis with donor lymphocyte infusion in a patient who had undergone human leukocyte antigen-haploidentical nonmyeloablative stem cell transplantation. Transplantation 77: 835-838, 2004.

34. Bregni M, Dodero A, Peccatori J, et al: Non-myeloablative conditioning followed by hematopoietic cell allografting and donor lymphocyte infusions for patients with metastatic renal and breast cancer. Blood 99: 4234-4236, 2002.

35. Childs RW, Clave E, Tisdale J, Plante M, Hensel N and Barrett J: Successful treatment of metastatic renal cell carcinoma with a non-myeloablative allogeneic peripheral blood progenitorcell transplant: evidence for a graft-versus-tumor effect. J Clin Oncol 17: 2044-2049, 1999.

36. Mosmann TR, Cherwinski H, Bond MW, Giedlin MA and Coffman RL: Two types of murine helper $\mathrm{T}$ cell clone. I, Definition according to profiles of lymphokine activities and secreted proteins. J Immunol 136: 2348-2357, 1986.

37. Chen Y, Kuchroo VK, Inobe J, Hafler DA and Weiner HL: Regulatory $\mathrm{T}$ cell clones induced by oral tolerance: suppression of autoimmune encephalomyelitis. Science 265: 1237-1240, 1994.
38. Mosmann TR and Sad S: The expanding universe of T-cell subsets: Th1, Th2 and more. Immunol Today 17: 138-146, 1996.

39. Paul WE and Seder RA: Lymphocyte responses and cytokines. Cell 76: 241-251, 1994

40. Nakamura K, Inaba M, Sugiura K, et al: Enhancement of allogeneic hematopoietic stem cell engraftment and prevention of GVHD by intra-bone marrow bone marrow transplantation plus donor lymphocyte infusion. Stem Cells 22: 125-134, 2004.

41. Blanc KL, Rasmusson I, Sundberg B, et al: Treatment of severe acute graft-versus-host disease with third party haploidentical mesenchymal stem cells. Lancet 363: 1439-1441, 2004.

42. Kuroiwa T, Kakishita E, Hamano T, et al: Hepatocyte growth factor ameliorates acute graft-versus-host disease and promotes hematopoietic function. J Clin Invest 107: 1365-1373, 2001.

43. Nicola MD, Carlo-Stella C, Magni M, et al: Human bone marrow stromal cells suppress T-lymphocyte proliferation induced by cellular or nonspecific mitogenic stimuli. Blood 99: 3838-3843, 2002.

44. Beyth S, Borovsky Z, Mevorach D, et al: Human mesenchymal stem cells after antigen-presenting cell maturation and induce T-cell unresponsiveness. Blood 105: 2214-2219, 2005.

45. Aggarwal $\mathrm{S}$ and Pittenger MF: Human mesenchymal stem cells modulate allogeneic immune cell responses. Blood 105 1815-1822, 2005.

46. Imado T, Iwasaki T, Kataoka Y, Kuroiwa T, Hara H, Fujimoto J and Sano H: Hepatocyte growth factor preserves graft-versusleukemia effect and T-cell reconstitution after marrow transplantation. Blood 104: 1542-1549, 2004

47. Blaser BW, Roychowdhury S, Kim DJ, et al: Donor-derived IL-15 is critical for acute allogeneic graft-versus-host disease. Blood 105: 894-901, 2005

48. Alpdogen O, Eng JM, Muriglan JS, et al: Interleukin-15 enhances immune reconstitution after allogeneic bone marrow trans plantation. Blood 105: 865-873, 2005

49. Sykes M, Sharabi Y and Sachs DH: Achieving alloengraftment without graft-versus-host disease: approaches using mixed allogeneic bone marrow transplantation. Bone Marrow Transplant 3: 379-386, 1988 .

50. Khouri IF, Saliba RM, Giralt SA, et al: Non-ablative allogeneic hematopoietic transplantation as adoptive immunotherapy for indolent lymphoma: low incidence of toxicity, acute graftversus-host disease, and treatment-related mortality. Blood 98: 3592-3599, 2001.

51. Kottaridis PD, Milligan DW, Chopra R, et al: In vivo CAMPATH$1 \mathrm{H}$ prevents graft-versus-host disease following non-myeloablative stem cell transplantation. Blood 96: 2419-2425, 2000.

52. Mattsson J, Uzunel M, Brune M, et al: Mixed chimaerism is common at the time of acute graft-versus-host disease and disease response in patients receiving non-myeloablative conditioning and allogeneic stem cell transplantation. Br J Haematol 115: 935-944, 2001. 